although a considerable absorption may occur if strong iodine ointments are left in contact with the skin for long periods. It seems certain, however, that it is unsafe to rely upon sufficient iodine being absorbed by the skin to produce the general therapentic effects of iodides.

The claim by the manufacturers that "Iodinosol is all absorbed promptly, thus ensuring prompt action and enabling the prescriber to regulate the dose of iodine to a decimal point of a grain," does not accord with our observations.

The agents are Messirs. E. T. Pearson and Co., London Road, Mitcham, Surrey.

\section{A Simple Aspirator.}

WITH reference to the description by Dr. H. O. Gunewardene of an aspirator, published in the BRITISH MEDICAL Journal of January 21st, p. 109, Dr. J. Ashforth (Wood ands, near Doncaster), writes that he has used a similar combined aspirating syringe and trocar, supplied by Messrs. Pettie and Whitelaw, of Aberdeen and Dundee, which he considers possesses advantages over that mentioned by Dr. Gunewardene, since no rubber tubing is required, and the whole apparatus is of metal, easily detachable and convenient to sterilize.

\section{MOTOR NOTES FOR MEDICAL MEN.} BY H. MASSAC BUIST.

The Care of the Car in Winter.

IN view of the large number of medical mon who nowadays look after their cars, in whole or in part, and of the apparent change from an unprecedented spell of mild weather to the normal temperatures of winter, a few hints may be helpful. This is a season in which it behoves the owner to noto the degree to which the motor-house is exposed. If it is facing due north, or east, and there is no warm compartment near it, because of the rapid changes of temperature likely to be experienced at this period, it is well to consider methods of artificial heating, or, alternatively, to make a practice of draining the water out of the radiator and cylinder jackets every night. The latter is a laborious course that occupies a considerable amount of time, particularly as the water has to be replenished in the morning. It is therefore in the nature of a last resort. Should the motor-house be sheltered from the coldest quarters, or built beneath a dwelling.place, such as a coachman's quarters, it will generally be unnecessary either to heat the garage artificially or to drain the water out of the cooler. In the case of the owner-driver I should always advise putting the car backwards into the garage in the summer months, then it stands conveniently for starting by hand. In any case, the minimum time is lost in getting away. By contrast, in cold weather the vehicle should be driven straight in and left so standing that it has to be backed out. Thus the vital parts will be farthest from the draught that can sweep in under the doors. But if there are no dwellings near the motor-house the question of artificial heating may require consideration.

A Simple Scheme for Occasional Heating.

Sometimes the simplest arrangements will suffice. It is not always necessary to install elaborate heating apparatus, particularly in face of the fact that such procedure may occasion trouble of the red-tape sort with the local autho. rities; also it may affect the fire insurance of the car. Some years ago, for two or three winters, I found the occasional use of an untipable paraffin lamp, costing ls., sufficient for the purpose, even in a garage at a relatively high altitude in a very cold county. Once filled, one of these lamps will burn for the best part of twelve hours. If it is put on the ground it will introduce considerable extra warmth into the ordinary coachhouse, even when the door is ill constructed and admits a draught at ground level.

When, however, there is no course but to drain the water system, one point should be had in mind in particular: after all the liquid has come away from the taps at the base of the cylinder casting and the cooler, the engine should be run a few moments to enable the water circulating purnp to expel any liquid in its neighbourhood. Many a case has occurred in which the owner has imagined he has expelled all the water from an engine system but has found subsequently that the mechanism has burst in the neighbourhood of the pump through the freezing of water that had accumulated and not been draiued away. This can be obviated by the simple method of running the engine for a few moments after the water circulation system has apparently drained itself empty by mere gravity. Usually the amount of petrol remaining in the pipe from the tank to the carburetter after the tap has been turned off will suffice to run the engine long enough for the purpose. Nor let anybody fear that running the engine in such circumstances in cold weather will cause difficulties. There is no such danger provided the lubrication system is adequately supplied with undiluted oil of the right grade. Whenever the water has been drained off, on preparing the car for use again hot filtered water should be used in preference to ordinary cold water. For one thing, that will vastly facilitate starting-up the engine.

Aids to Starting.

Much remains to be done in the way of making cars easier to start in cold weather. When hand cranking was the rule more attention used to be given to this matter, despite the fact that, the further back we go, proportionately the easier engines were to start. On the one hand, in the pre-war period the quality of the fuel was better than the average available to-day, and, on the other, the compressions used for standardized car engines were lower, therefore it was not necessary to cranl them as fast to get a start as is essential with post-war designs. Since the coming of the mechanical enginestarter, however, the need for easy starting has been largely overlooked, with the result that great burden is placed on the battery, and often much trouble results. By letting the mechanical engine starter turn the crankshaft for many seconds at a time without the mixture being fired, fuel may pass the pistons and, falling into the basechamber, dilute the lubricating oil. Experiments recently carried out by an American manufacturer who had frequent troubles of this kind are reported to me privately to have shown that thirty seconds of cranking with a mechanical engine-starter, and with the throttle closed, resulted in half a pint of fuel flowing by the pistons into the crank case. Four cranking periods of this duration each day would thus result not only in wasting a quart of fuel, but a serious dilution of the lubricating oil, with all its grave risks. Such a case, however, must be regarded as altogether exceptional. But it is useful to have it in mind as an indication of a very prevalent source of trouble which may be experienced, in less degree, by any motorist. The better the construction the more important it is that no foreign matter should get mixed with tho lubricant. A quarter of a pint of foreign liquid in the base chamber of some engines would bo sufficient to render the best lubricant quite incapable of doing its work.

When and Honv to Use Aviation Spirit by the Cupful.

A large percentage of cars are kept in unheated motor. houses, or are allowed to stand in front of doors for long spells during which the engine becomes cold. 'The higher the compression of the power plant the more rapidly the crankshaft has to be turned to have a chance of starting Moreover, as there is every prospect that the fuels which will be supplied for service in cars will not tend to improve' in quality, the importance of obtaining a quicker average start, as well as of controlling the cooling system whereby the engine temperature can be warmed up promptly to the degree required for correct operation, is worthy of study. While these problems largely concern the motor engineer and car builder, the medical man can do much to assist and protect himself in this connexion. For example, the use of radiator masks is now well understood in this country, particularly by doctors. Quilted masks are probably the best sort for medical men. It is not necessary, however, that the covering should extend over the whole of the bonnet; the important part is the radiator.

In regard to starting the engine from cold, a great many cars are equipped with carburetters a feature of which is that the undoing of two nuts, or even the sliding of a finger aideways, exposes the float chamber. All carburetters ought to have a drain tap at the base. All users ought to turn off the petrol tap when the vehicle is needed no longer. A good practice to ensure the best possible start in cold weather is to turn off the tap at the end of the day, and run the engine until the fuel in the carburetter is exhausted. On going to start the car up next day the fuel tap should still be left turned off. A tin of aviation spirit should be kept in stock. When needed a small bottle is filled with this spirit, and a little is poured into the float chamber, the top of which should then be put on promptly and the throttle left in the usual position for starting. By means of this best grade spirit it should be possible to get a very ready start by hand. or by means of the electric gear, in 
the worst of weather, for this fuel is equal to the best pre-war motor car petrol. As soon as the engine gets going, the fuel tap can be turned on. Thus there will be a gradual mixture of this spirit with the other, and, by the time the blend is used, the engine will be sufficiently warm for the ordinary fuel to serve the purpose. When the carburetter is inaccessible, it may pay to fit a quarter-gallon supplementary tank under the bonnet and a short pipe with a two-way cock connected with the main fuel pipe, whereby, for starting, aviation spirit can be used. No car should be started on benzol in cold weather.

How to Set Out.

The radiator hood should be kept on until the engine is at its full working temperature. Sometines this will mean a quarter of an hour's going in really cold weather. It will make for petrol economy, as well as give a much better pick up. The habit of putting the accelerator full down when the engine begins running is not to be recommended. It leads to unnecessary waste oi fuel through imperfect combustion and involves the grave risk of unburnt fuel getting past the pistons into the lubrication system. A tin of aviation spirit used in the way I indicate, even if some of its contents be employed twice a day-as, for example, to start the car after it las been idle for several hours in the middle of the day-will, nevertheless, last one through the best part of a winter. Indeed, as in this way a quicker start is achieved, it is an actual net saving, because less fuel is passed wastefully through the engine system before the gas begins to fire. Therefore the method is both satisfactory and cheaper. Once a modern engine is running it is easier to warm than older types, because the carburetter intake pipe of most latter day constructions is water-jacketed, or a "hot spot" system is used, consequently as soon as the water begins to increase in temperature the vaporization of the fuel is achieved more perfectly and more readily. The degree of heat necessary for vaporization may be obtained by the use of an electrical heating element, as in the system pioneered by Cadillac, or by burning a small amount of fuel. Primers using fuel which is easily vaporized even at quite low temperatures have also beeu employed with satisfaction in some instances, but are scarcely general on the home market. Moreover, one scarcely advises the introduction of apparatus of this sort by individuals. Rather should such developments be looked for in the direction of devices standardized by manufacturers on car's as a result of their orvn necessarily extensive and prolonged experiments. Probably all devices, or systems, used to aid in starting an engine have certain drawbacks as well as points of advantage. The need for a simple, dependable, and inexpensive device for this purpose, such as can be standardized by all makers, is becoming increasingly evident, particularly as fuel is made less and less volatile. Neantime, most car users will find they can get on well enough by the use of one or other of the foregoing hints.

\section{TIIE SCHOOL MEDICAL SERVICE.}

\section{Adnress by Sir George Newman.}

THE special course of instruction for the school medical service which has been arranged at the London Hospital was opened on February lst with an introductory address by Sir George Newman, Chief Medical Officer to the Ministry of Health and the Board of Education. The chair was taken by Lord DAwson, who explained that the course was not only for school medical officers but for those who intended to combine general practice with work at the school clinics on a part-time basis.

Sir George Newhan said that the course was an experiment. Its first purpose was to draw the attention of school medical officers and assistant officers to the clinical aspects of their work. There were now 300 whole-time school medical officers and 500 whole-time assistant officers, and the difficulty al ways in such administrative posts was to retain the clinical spirit. The second purpose of the course was to help general practitioners to understand a little more fully what the school medical service was and involved. When school medical inspection started many general practitioners mis understood the situation. Some thought that child patients were being taken from them, which was not the case; others

1 See l3nitish Medical Jolnina, January 7th, 1922, p. 27 that they themselves ought to do the inspection, and they were invited to do it but found it impracticable. Under this service over two million children were medically inspected annually in the 22,000 public elementary schools, so that the entire population of school age was covered every three years. Children found to be defective were referred in the first instance to general practitioners, and tens of thousands of children were now receiving treatment from such practitioners. There were certain conditions, however, which the private practitioner did not want to treat because treatment was too tedious or for other reasons could not well be integrated into ordinar'y practice. 'These were eye cases, ear, nose and throat cases, skin complaints, minor ailments, and dental cases, which five branches of treatment had therefore been referred to hospitals and special clinics. Sir George Newman hoped that the course would be a means of drawing attention to the importance of studying disease in the child. From the medical aspect children's diseases were important because they were the beginnings of all disease; from the social aspect, because if the problem of the child's health were solved, the problem of the national health would adjust itself. The great body of infections, for instance, which began in childhood laid tine basis for future constitutional weakness. Another line of study concerned those infant diseases which were carried on into school age. Of the children who came to school at 5, approximately 37 per cent. were suffering from some physical or mental defect. A task before the school medical service was so to differentiate the conditions found in children between the ages of 5 and 14 as to determine what it was below the age of 5 which prepared the child's body for subsequent disease. Then it was necessary to study the causes of infant mortality, which was the most sensitive index to the health of the community, more so than the general death rate. Finally, the school medical service, which was the logical outcome of compulsory education, must be closely co-ordinated with the public health service. It had been too long assumed that the public health service was mainly concerned with environment. The essential element in preventive medicine was the person, and it was from environment to the person that the centre of gravity in the public health service must gradually but steadily shift. The relation of morbidity returns to environ ment was indirect; their relation to the habits and practices of the individual was direct.

Sir George Newman went on to emphasize the fact that the school medical service was an instance of local autonomy. It was the responsibility of the 318 local education authorities, and the function of the central government was to supervise and to secure a measure of uniformity. The service started with inspection. Originally they were pressed to make the inspection of an elaborate anthropometric character, preparatory to a complete physical survey of the English people; but this was turned down because the examination of each child would have taken from thirty to sixty minutes, and might have irritated the child and have been misunderstood by the parents. The present inspection could be carried out in from four to seven minutes. The parent still had the right to refuse to have his child inspected, but the percentage of objections, never high, was now at vanishing point. Next came medical treatment, rendered necessary not only in the case of the five classes of ailments and defects just mentioned, but in the case of families who had no medical attendant to whom the children could be referred. The clinics now numbered 900 .

He thought it an advantage to have whole-time officers to undertake inspection, but he was equally persuaded that for medical treatment there were great advantages in having part-timedoctors who were practising clinical medicine and surgery in the district. The Government had done its best to encourage local authorities to staff their clinics on this principle; long before it became statutory for the local authority, in making provision for medical treatment, to con. sider how far that treatment could be provided by the private practitioners of the area before setting up any distinct machinery, that had been the policy of the Board of Education. There were at present under local authorities 730 general private practitioners at work in the school seivice, not to mention others in institutions. In conclusion Sir George Newman sketched briefly some of the other elements in the school service: the provision of special schools for defectives and of sanatorium schools, school meals for the ill-nourished, physical training, and the teaching of personal and school hygiene. 